\title{
UNDERSTAND OF CUSTOMER SATISFACTION AND PURCHASING BEHAVIOR: A STUDY AT MCDONALD IN BANDUNG
}

\author{
Vincentius Leonardo Kweeswara, Hadi Kusumah \\ Master of Computer Student, STMIK LIKMI, Indonesia \\ Master of Computer Student, STMIK LIKMI, Indonesia
}

Email: vincent.leo9306@yahoo.com

\section{ARTICLE INFO}

Date received : 01 August 2020

Revision date : 25 August 2020

Date received : 10 September 2020

Keywords:

Customer Satisfaction

Customer Behaviour

Customer Perception

Franchise

Purchaising Behaviour
ABSTRACT

This research was created for understand customer purchasing behavior and customer satisfaction in McDonald. This research was focus in Bandung, West Java, Indonesia. Base on history of McDonald, Fast food outlets have started to develop in the 19th century. In the 20th century, fast food restaurant business began to spread to Europe, Africa, Australia and Asia such as Indonesia through franchising or franchise concept. However local business can make competitive market with McDonald. This research will help McDonald to evaluate they performance in market. With this research McDonald can know which area they need to improve and suggestion for McDonald to increase their sales. With this research McDonald can know which are make customer satisfaction and which area make customer dissatisfaction. This research takes six major factors that have impact with customer satisfaction. Those factors are price, quality, promotion, sales personnel or staff, display, and location. This research will use survey method to gain some information from customer. After collect some data and information. This research will use SPSS to process the data to know which hypotheses is accepted and rejected. Method using by this research in SPSS is ANOVA. ANOVA will give a significant point for every question to know the result can accept or reject. Result of this paper base on sic major factor are important. For the crucial factor are The most factor, which have biggest impact, are quality and promotion. Quality and promotion have the lower significant. All value in quality and promotion factor was accepted. It mean quality and promotion are the most influencing factors.

\section{INTRODUCTION}

Fast-food restaurant business is one of the few companies that require maximum services and high professionalism. Increasing competition among firms like today, inevitably makes the company's management should be more careful in determining its strategy to compete with its competitors. Competition coming not only from abroad, but there are fast food outlets within the country. The purpose of all this is none other than to win the competition with the existing competitors. From a marketing perspective on the competitive situation is so, then in order to come out as winners, the management 
company is expected to design and implement a marketing strategy that is able to create, maintain and improve consumer satisfaction.

In addition to the taste and quality of food, quality of service and good performance is also very supportive of customer satisfaction. Customer satisfaction can influence customer behavior especially customer loyalty manifested itself in a desire and intention to repurchase recommend. Efforts to retain loyal customers is a challenge for employers, customers now more critical in choosing foods according to the price, this is not easy given the many changes can occur at any time in the customer themselves. Quality of service provides a special incentive for customers to establish mutually beneficial relationship ties in the long term with the company. This kind of emotional bond allows the company to understand carefully the specific expectations and needs of customers. Intense competition encourages manufacturers to produce products or services that have high competitiveness in an attempt to win the market.

This research held in 2016 when franchise business was popular as a busniss. In that time Mcdonal was one of the huge business in fast food industry doing francise and become inspiration to competitor.

\section{Research Question}

1. To understand customer perception toward price of product in McDonald.

2. To understand customer perception toward quality of product in McDonald.

3. To understand customer perception toward promotion given by McDonald.

4. To understand customer perception toward staff in McDonald in Bandung.

5. To understand customer perception toward display overall of McDonald.

6. To understand customer perception toward location of McDonald.

\section{Objectives of the Research}

As identified earlier, the progress of McDonald is quickly accumulative and the opposition between other fast foods becomes higher level as well. Fast food is American trend which popular in Asia. Especially is Indonesia, which have the fourth bigger population in the world. That is why McDonald should thinking more creativity and innovation to be successful and growing the business, supervisor or the commercial owner (franchisee) must pay extra care and focus hooked on the competitive advantages. It is have several methods to make a competitive advantage, and taking a good respect considerate about the consumers is measured as the way to make customer value, which determination advantage the store. One of the greatest vital segments of determining a industry is to understand what issues those have impact to customer in the way of creating a purchase choice. By the considerate of customer behavior and acquaintance about what can effect them in creating a purchase choice, the industry can survive, growing, innovation and make an effective strategy.

By this finding, this research can help the owner (franchisee) or supervisor to apply the greatest suitable strategy and planning, which can make company competitive advantage. Thus, this research have include 2 point purposes, it is:

1. To classify and quantify customer perception on fast food product and service at McDonald.

2. To assess the influence of fast food products regarding customer satisfaction at McDonald.

\section{METODE}

Fact is that today, there are a variety of brands and fast food company in Bandung, which will affect the higher competition among fast-food company. Therefore, each market must have a competitive advantage to survive and stay profitable consistency. The purpose of this research is to know what factors make the customer comfortable. By using the approach of consumer behavior, this research concerns the understanding of the influence of fast food marketing on consumer purchasing behavior, customer satisfaction. Consumers have an important role in the ongoing effort. This research may be useful for the McDonald or any party who want to make business in the fast food sector. Based on the fact that there are some fast food company chose Bandung as a place to make business. Unlike some local competitors are able to beat McDonald's in the fast food sector.

\section{Research Method}

In this methodology, the questionnaire is used as part of a survey-based method. Base on Cooper (2014) the questionnaire contains of adding to the questions in the order printed or typed ambiguous on the form or set of methods. Go quantitative comes within range applied and used based survey, this study uses the most important data as a source. Primary data is getting to collect numerical data from respondents using questionnaires as a medium. This resulted in the primary data to test the hypothesis. What is more, there are several methods for collecting data via survey-based methodologies such as Internet surveys, telephone surveys, and a private survey. This was conveyed to the potential and is responsible for answering and returning back the questionnaire. Base on ho (2014) this study uses SPSS to check the answers from this survey that target samples do. Not only that, this research also can control the target sample so that answers from the survey could not sample any. 


\section{Research Model}

Based on the conceptual structure and the research objectives, several hypotheses have been developed by the researcher as follows:

$\mathrm{H} 1$ : Price has a positive and important to influence on the customer satisfaction.

H2: Quality has a positive and important to influence on the customer satisfaction.

H3: Promotion has a positive and important to influence on the customer satisfaction.

$\mathrm{H} 4$ : Staff have a positive and important to influence on the customer satisfaction.

H5: Display has a positive and important to influence on the customer satisfaction.

H6: Location has a positive and important to influence on the customer satisfaction.

\section{RESULTS AND DISCUSSION \\ Factor 1: Price \\ Sub Hypothesis 1a}

Ha: McDonald has a cheaper package price than other competitor affect customer satisfaction in McDonald

Ho: McDonald has a cheaper package price than other competitor does not affect customer satisfaction in McDonald.

This table is the analysis of variance (ANOVA) test among the variable rate of purchase product at McDonald in Bandung and regarding to price base on age before making decision a purchase on a McDonald. In this test, looking up in price is the independent variable, this test looking up rate of purchase as a dependent variable. The result are being demonstrated: $p$-value $=0.000<\alpha=0.05$

From this figure, the alpha value $\alpha$ is bigger than the $p$ value. When alpha value is bigger than $p$ value, the result shows the test was accepted. The result shows hypothesis is accepted. It means price is affecting customer satisfaction base on different age or generation.

\section{Sub Hypotheses 1b}

$\mathrm{Hb}$ : McDonald display the price clearly affects customer satisfaction in McDonald

Ho: McDonald display the price clearly affects does not affect customer satisfaction in McDonald.

This table is the analysis of variance (ANOVA) test among the variable rate of purchase product at McDonald in Bandung and regarding to price base on age before making decision a purchase on a McDonald. In this test, looking up in price is the independent variable, this test looking up rate of purchase as a dependent variable. The result are being demonstrated: $p$-value $=0.059>\alpha=0.05$ From this figure, the alpha value $\alpha$ is smaller than the $p$ value. When alpha value is smaller than $p$ value, the result shows the test was rejected. The result shows hypothesis is rejected. It means price is affecting customer satisfaction base on different age or generation.

\section{Sub Hypotheses 1c}

Hc: McDonald has a offered at affordable price affect customer satisfaction in McDonald

Ho: McDonald has a offered at affordable price does not affect customer satisfaction in McDonald

This table is the analysis of variance (ANOVA) test among the variable rate of purchase product at McDonald in Bandung and regarding to price base on age before making decision a purchase on a McDonald. In this test, looking up in price is the independent variable, this test looking up rate of purchase as a dependent variable. The result are being demonstrated: $p$-value $=0.000<\alpha=0.05$

From this figure, the alpha value $\alpha$ is bigger than the $p$ value. When alpha value is bigger than $p$ value, the result shows the test was accepted. The result shows hypothesis is accepted. It means price is affecting customer satisfaction base on different age or generation.

\section{Sub Hypotheses 1d}

$\mathrm{Hd}$ : The quality of the foods offered is worth the price affect customer satisfaction in McDonald

Ho: The quality of the foods offered is worth the price does not affect customer satisfaction in McDonald

This table is the analysis of variance (ANOVA) test among the variable rate of purchase product at McDonald in Bandung and regarding to price base on age before making decision a purchase on a McDonald. In this test, looking up in price is the independent variable, this test looking up rate of purchase as a dependent variable. The result are being demonstrated: $p$-value $=0.000<\alpha=0.05$

From this figure, the alpha value $\alpha$ is bigger than the $p$ value. When alpha value is bigger than $p$ value, the result shows the test was accepted. The result shows hypothesis is accepted. It means price is affecting customer satisfaction base on different age or generation.

\section{Sub Hypotheses 1e}

He: McDonald offers different price depending on their time ordered affect customer satisfaction in McDonald

Ho: McDonald offers different price depending on their time ordered does not affect customer satisfaction in McDonald

This table is the analysis of variance (ANOVA) test among the variable rate of purchase product at McDonald in Bandung and regarding to price base on age before making decision a purchase on a McDonald. In this test, looking up in price is the independent variable, this test looking up rate of purchase as a dependent variable. The result are being demonstrated: $p$-value $=0.000<\alpha=0.05$ 
From this figure, the alpha value $\alpha$ is bigger than the $p$ value. When alpha value is bigger than $p-$ value, the result shows the test was accepted. The result shows hypothesis is accepted. It means price is affecting customer satisfaction base on different age or generation.

\section{Sub Hypotheses $1 f$}

Hf: McDonald provides a Varity of price according to the size of the package affect customer satisfaction in McDonald

Ho: McDonald provides a Varity of price according to the size of the package does not affect customer satisfaction in McDonald

This table is the analysis of variance (ANOVA) test among the variable rate of purchase product at McDonald in Bandung and regarding to price base on age before making decision a purchase on a McDonald. In this test, looking up in price is the independent variable, this test looking up rate of purchase as a dependent variable. The result are being demonstrated: $p$-value $=0.190>\alpha=0.05$

From this figure, the alpha value $\alpha$ is smaller than the $p$ value. When alpha value is smaller than $\mathrm{p}$-value, the result shows the test was rejected. The result shows hypothesis is rejected. It means price is affecting customer satisfaction base on different age or generation.

\section{Factor 2: Quality}

\section{Sub Hypothesis 2a}

$\mathrm{Ha}$ : McDonald use fresh ingredient affect customer satisfaction in McDonald

Ho: McDonald use fresh ingredient does not affect customer satisfaction in McDonald.

This table is the analysis of variance (ANOVA) test among the variable rate of purchase product at McDonald in Bandung and regarding to quality base on age before making decision a purchase on a McDonald. In this test, looking up in quality is the independent variable, this test looking up rate of purchase as a dependent variable. The result are being demonstrated: $p$-value $=0.000<\alpha=0.05$

From this figure, the alpha value $\alpha$ is bigger than the $p$ value. When alpha value is bigger than $p$ value, the result shows the test was accepted. The result shows hypothesis is accepted. It means quality is affecting customer satisfaction base on different age or generation.

\section{Sub Hypotheses 2b}

$\mathrm{Hb}$ : McDonald always have a constant taste affects customer satisfaction in McDonald

Ho: McDonald always have a constant taste affects does not affect customer satisfaction in McDonald.

This table is the analysis of variance (ANOVA) test among the variable rate of purchase product at McDonald in Bandung and regarding to quality base on age before making decision a purchase on a
McDonald. In this test, looking up in quality is the independent variable, this test looking up rate of purchase as a dependent variable. The result are being demonstrated: $p$-value $=0.014<\alpha=0.05$

From this figure, the alpha value $\alpha$ is bigger than the $p$ value. When alpha value is bigger than $p$ value, the result shows the test was accepted. The result shows hypothesis is accepted. It means quality is affecting customer satisfaction base on different age or generation.

\section{Sub Hypotheses 2c}

Hc: McDonald use high ingredient affect customer satisfaction in McDonald

Ho: McDonald use high ingredient does not affect customer satisfaction in McDonald

This table is the analysis of variance (ANOVA) test among the variable rate of purchase product at McDonald in Bandung and regarding to quality base on age before making decision a purchase on a McDonald. In this test, looking up in quality is the independent variable, this test looking up rate of purchase as a dependent variable. The result are being demonstrated: $p$-value $=0.000<\alpha=0.05$

From this figure, the alpha value $\alpha$ is bigger than the $p$ value. When alpha value is bigger than $p$ value, the result shows the test was accepted. The result shows hypothesis is accepted. It means quality is affecting customer satisfaction base on different age or generation.

\section{Sub Hypotheses 2d}

$\mathrm{Hd}$ : McDonald always keep kitchen clean affect customer satisfaction in McDonald

Ho: McDonald always keep kitchen clean does not affect customer satisfaction in McDonald

This table is the analysis of variance (ANOVA) test among the variable rate of purchase product at McDonald in Bandung and regarding to quality base on age before making decision a purchase on a McDonald. In this test, looking up in quality is the independent variable, this test looking up rate of purchase as a dependent variable. The result are being demonstrated: $p$-value $=0.002<\alpha=0.05$

From this figure, the alpha value $\alpha$ is bigger than the $p$ value. When alpha value is bigger than $p$ value, the result shows the test was accepted. The result shows hypothesis is accepted. It means quality is affecting customer satisfaction base on different age or generation.

\section{Sub Hypotheses $2 e$}

He: McDonald always serve the foods freshly affect customer satisfaction in McDonald

Ho: McDonald always serve the foods freshly does not affect customer satisfaction in McDonald

This table is the analysis of variance (ANOVA) test among the variable rate of purchase product at McDonald in Bandung and regarding to quality base on age before making decision a purchase on a 
McDonald. In this test, looking up in quality is the independent variable, this test looking up rate of purchase as a dependent variable. The result are being demonstrated: $p$-value $=0.000<\alpha=0.05$

From this figure, the alpha value $\alpha$ is bigger than the $p$ value. When alpha value is bigger than $p$ value, the result shows the test was accepted. The result shows hypothesis is accepted. It means quality is affecting customer satisfaction base on different age or generation.

Factor 3: Promotion

\section{Sub Hypothesis 3a}

$\mathrm{Ha}$ : I purchased McDonald because of the promotion offered by banks affect customer satisfaction in McDonald

Ho: I purchased McDonald because of the promotion offered by banks does not affect customer satisfaction in McDonald.

This table is the analysis of variance (ANOVA) test among the variable rate of purchase product at McDonald in Bandung and regarding to promotion base on age before making decision a purchase on a McDonald. In this test, looking up in promotion is the independent variable, this test looking up rate of purchase as a dependent variable. The result are being demonstrated: $p$-value $=0.000<\alpha=0.05$

From this figure, the alpha value $\alpha$ is bigger than the $p$ value. When alpha value is bigger than $p$ value, the result shows the test was accepted. The result shows hypothesis is accepted. It means promotion is affecting customer satisfaction base on different age or generation.

\section{Sub Hypotheses $3 b$}

$\mathrm{Hb}$ : I purchased McDonald foods because it provides gifts for children affects customer satisfaction in McDonald

Ho: I purchased McDonald foods because it provides gifts for a child does not affect customer satisfaction in McDonald.

This table is the analysis of variance (ANOVA) test among the variable rate of purchase product at McDonald in Bandung and regarding to promotion base on age before making decision a purchase on a McDonald. In this test, looking up in promotion is the independent variable, this test looking up rate of purchase as a dependent variable. The result are being demonstrated: $p$-value $=0.000<\alpha=0.05$

From this figure, the alpha value $\alpha$ is bigger than the $p$ value. When alpha value is bigger than $p$ value, the result shows the test was accepted. The result shows hypothesis is accepted. It means promotion is affecting customer satisfaction base on different age or generation.

\section{Sub Hypotheses 3c}

$\mathrm{Hc}$ : I purchased McDonald foods because of the promotion using e-card (T-cash) affect customer satisfaction in McDonald
Ho: I purchased McDonald a food because of the promotion using e-card (T-cash) does not affect customer satisfaction in McDonald

This table is the analysis of variance (ANOVA) test among the variable rate of purchase product at McDonald in Bandung and regarding to promotion base on age before making decision a purchase on a McDonald. In this test, looking up in promotion is the independent variable, this test looking up rate of purchase as a dependent variable. The result are being demonstrated: $p$-value $=0.002<\alpha=0.05$

From this figure, the alpha value $\alpha$ is bigger than the $p$ value. When alpha value is bigger than $p$ value, the result shows the test was accepted. The result shows hypothesis is accepted. It means promotion is affecting customer satisfaction base on different age or generation.

\section{Sub Hypotheses 3d}

$\mathrm{Hd}$ : McDonald have happy hour promotion affect customer satisfaction in McDonald

Ho: McDonald have happy hour promotion does not affect customer satisfaction in McDonald

This table is the analysis of variance (ANOVA) test among the variable rate of purchase product at McDonald in Bandung and regarding to promotion base on age before making decision a purchase on a McDonald. In this test, looking up in promotion is the independent variable, this test looking up rate of purchase as a dependent variable. The result are being demonstrated: $p$-value $=0.000<\alpha=0.05$

From this figure, the alpha value $\alpha$ is bigger than the $p$ value. When alpha value is bigger than $p$ value, the result shows the test was accepted. The result shows hypothesis is accepted. It means promotion is affecting customer satisfaction base on different age or generation.

\section{Sub Hypotheses $3 e$}

He: I purchased product in McDonald because of free drive thru service affect customer satisfaction in McDonald

Ho: I purchased product in McDonald because of free drive thru service does not affect customer satisfaction in McDonald

This table is the analysis of variance (ANOVA) test among the variable rate of purchase product at McDonald in Bandung and regarding to promotion base on age before making decision a purchase on a McDonald. In this test, looking up in promotion is the independent variable, this test looking up rate of purchase as a dependent variable. The result are being demonstrated: $p$-value $=0.015<\alpha=0.05$

From this figure, the alpha value $\alpha$ is bigger than the $p$ value. When alpha value is bigger than $p$ value, the result shows the test was accepted. The result shows hypothesis is accepted. It means promotion is affecting customer satisfaction base on different age or generation. 


\section{Factor 4: Staff}

\section{Sub Hypothesis 4a}

$\mathrm{Ha}$ : McDonald's staff offers and explains promotions happening clearly affect customer satisfaction in McDonald

Ho: McDonald's staff offers and explains a promotion happening clearly does not affect customer satisfaction in McDonald.

This table is the analysis of variance (ANOVA) test among the variable rate of purchase product at McDonald in Bandung and regarding to staff base on age before making decision a purchase on a McDonald. In this test, looking up in staff is the independent variable, this test looking up rate of purchase as a dependent variable. The result are being demonstrated: $p$-value $=0.010<\alpha=0.05$

From this figure, the alpha value $\alpha$ is bigger than the $p$ value. When alpha value is bigger than $p$ value, the result shows the test was accepted. The result shows hypothesis is accepted. It means staff is affecting customer satisfaction base on different age or generation.

\section{Sub Hypotheses 4b}

$\mathrm{Hb}$ : Sales personnel of McDonald is really helpful during the purchasing process affects customer satisfaction in McDonald

Ho: Sales personnel of McDonald is really helpful during the purchasing process affects does not affect customer satisfaction in McDonald.

This table is the analysis of variance (ANOVA) test among the variable rate of purchase product at McDonald in Bandung and regarding to staff base on age before making decision a purchase on a McDonald. In this test, looking up in staff is the independent variable, this test looking up rate of purchase as a dependent variable. The result are being demonstrated: $p$-value $=0.016<\alpha=0.05$

From this figure, the alpha value $\alpha$ is bigger than the $p$ value. When alpha value is bigger than $p$ value, the result shows the test was accepted. The result shows hypothesis is accepted. It means staff is affecting customer satisfaction base on different age or generation.

\section{Sub Hypotheses 4c}

$\mathrm{Hc}$ : If I have some questions about product in McDonald, sales personnel can explain my questions clearly affect customer satisfaction in McDonald

Ho: If I have some questions about product in McDonald, sales personnel can explain my questions clearly does not affect customer satisfaction in McDonald

This table is the analysis of variance (ANOVA) test among the variable rate of purchase product at McDonald in Bandung and regarding to staff base on age before making decision a purchase on a McDonald. In this test, looking up in staff is the independent variable, this test looking up rate of purchase as a dependent variable. The result are being demonstrated: $p$-value $=0.007<\alpha=0.05$

From this figure, the alpha value $\alpha$ is bigger than the $p$ value. When alpha value is bigger than $p$ value, the result shows the test was accepted. The result shows hypothesis is accepted. It means staff is affecting customer satisfaction base on different age or generation.

\section{Sub Hypotheses 4d}

Hd: Sales personnel in McDonald is respectful and friendly affect customer satisfaction in McDonald

Ho: Sales personnel in McDonald is respectful and friendly does not affect customer satisfaction in McDonald

This table is the analysis of variance (ANOVA) test among the variable rate of purchase product at McDonald in Bandung and regarding to staff base on age before making decision a purchase on a McDonald. In this test, looking up in staff is the independent variable, this test looking up rate of purchase as a dependent variable. The result are being demonstrated: $p$-value $=0.008<\alpha=0.05$

From this figure, the alpha value $\alpha$ is bigger than the $p$ value. When alpha value is bigger than $p$ value, the result shows the test was accepted. The result shows hypothesis is accepted. It means staff is affecting customer satisfaction base on different age or generation.

\section{Sub Hypotheses $4 e$}

He: McDonald's staff provides fast service in response to consumer demands affect customer satisfaction in McDonald

Ho: McDonald's staff provides fast service in response to consumer demands does not affect customer satisfaction in McDonald

This table is the analysis of variance (ANOVA) test among the variable rate of purchase product at McDonald in Bandung and regarding to staff base on age before making decision a purchase on a McDonald. In this test, looking up in staff is the independent variable, this test looking up rate of purchase as a dependent variable. The result are being demonstrated: $p$-value $=0.220<\alpha=0.05$

From this figure, the alpha value $\alpha$ is bigger than the $p$ value. When alpha value is bigger than $p$ value, the result shows the test was accepted. The result shows hypothesis is accepted. It means staff is affecting customer satisfaction base on different age or generation.

\section{Sub Hypotheses $4 e$}

$\mathrm{He}$ : McDonald's staff is always willing to respond to consumer complaints affect customer satisfaction in McDonald

Ho: McDonald's staff is always willing to respond to consumer complaints does not affect customer satisfaction in McDonald 
This table is the analysis of variance (ANOVA) test among the variable rate of purchase product at McDonald in Bandung and regarding to staff base on age before making decision a purchase on a McDonald. In this test, looking up in staff is the independent variable, this test looking up rate of purchase as a dependent variable. The result are being demonstrated: $p$-value $=0.005<\alpha=0.05$

From this figure, the alpha value $\alpha$ is bigger than the $p$ value. When alpha value is bigger than $p$ value, the result shows the test was accepted. The result shows hypothesis is accepted. It means staff is affecting customer satisfaction base on different age or generation.

\section{Factor 5: Display \\ Sub Hypotheses 5a}

Ha: McDonald provides enough table and chair for dining in affect customer satisfaction in McDonald

Ho: McDonald provides enough table and chair for dining in does not affect customer satisfaction in McDonald

This table is the analysis of variance (ANOVA) test among the variable rate of purchase product at McDonald in Bandung and regarding to display base on age before making decision a purchase on a McDonald. In this test, looking up in display is the independent variable, this test looking up rate of purchase as a dependent variable. The result are being demonstrated: $p$-value $=0.229>\alpha=0.05$

From this figure, the alpha value $\alpha$ is smaller than the $p$ value. When alpha value is smaller than $\mathrm{p}$-value, the result shows the test was rejected. The result shows hypothesis is rejected. It means display is affecting customer satisfaction base on different age or generation.

\section{Sub Hypotheses 5b}

$\mathrm{Hb}$ : McDonald keep the cleanliness of the store affect customer satisfaction in McDonald

Ho: McDonald keep the cleanliness of the store does not affect customer satisfaction in McDonald

This table is the analysis of variance (ANOVA) test among the variable rate of purchase product at McDonald in Bandung and regarding to display base on age before making decision a purchase on a McDonald. In this test, looking up in display is the independent variable, this test looking up rate of purchase as a dependent variable. The result are being demonstrated: $p$-value $=0.127>\alpha=0.05$

From this figure, the alpha value $\alpha$ is smaller than the $p$ value. When alpha value is smaller than $p$-value, the result shows the test was rejected. The result shows hypothesis is rejected. It means display is affecting customer satisfaction base on different age or generation.

\section{Sub Hypotheses 5c}

Hc: Products are neatly displayed in the shelves affect customer satisfaction in McDonald

Ho: Products are neatly displayed in the shelves does not affect customer satisfaction in McDonald

This table is the analysis of variance (ANOVA) test among the variable rate of purchase product at McDonald in Bandung and regarding to display base on age before making decision a purchase on a McDonald. In this test, looking up in display is the independent variable, this test looking up rate of purchase as a dependent variable. The result are being demonstrated: $p$-value $=0.001<\alpha=0.05$

From this figure, the alpha value $\alpha$ is bigger than the $p$ value. When alpha value is bigger than $p$ value, the result shows the test was accepted. The result shows hypothesis is accepted. It means display is affecting customer satisfaction base on different age or generation.

\section{Sub Hypotheses $5 d$}

Hd: McDonald provides children facilities affect customer satisfaction in McDonald

Ho: McDonald provides a children facility does not affect customer satisfaction in McDonald

This table is the analysis of variance (ANOVA) test among the variable rate of purchase product at McDonald in Bandung and regarding to display base on age before making decision a purchase on a McDonald. In this test, looking up in display is the independent variable, this test looking up rate of purchase as a dependent variable. The result are being demonstrated: $p$-value $=0.064>\alpha=0.05$

From this figure, the alpha value $\alpha$ is smaller than the $p$ value. When alpha value is smaller than $p$-value, the result shows the test was rejected. The result shows hypothesis is rejected. It means display is affecting customer satisfaction base on different age or generation.

\section{Sub Hypotheses $5 e$}

$\mathrm{He}$ : McDonald have an interesting exterior design affect customer satisfaction in McDonald

Ho: McDonald have an interesting exterior design does not affect customer satisfaction in McDonald

This table is the analysis of variance (ANOVA) test among the variable rate of purchase product at McDonald in Bandung and regarding to display base on age before making decision a purchase on a McDonald. In this test, looking up in display is the independent variable, this test looking up rate of purchase as a dependent variable. The result are being demonstrated: $p$-value $=0.001<\alpha=0.05$

From this figure, the alpha value $\alpha$ is bigger than the $p$ value. When alpha value is bigger than $p$ value, the result shows the test was accepted. The result shows hypothesis is accepted. It means display is affecting customer satisfaction base on different age or generation. 


\section{Sub Hypotheses $5 f$}

Hf: McDonald have a unique interior affect customer satisfaction in McDonald

Ho: McDonald have a unique interior does not affect customer satisfaction in McDonald

This table is the analysis of variance (ANOVA) test among the variable rate of purchase product at McDonald in Bandung and regarding to display base on age before making decision a purchase on a McDonald. In this test, looking up in display is the independent variable, this test looking up rate of purchase as a dependent variable. The result are being demonstrated: $p$-value $=0.000<\alpha=0.05$

From this figure, the alpha value $\alpha$ is bigger than the $p$ value. When alpha value is bigger than $p$ value, the result shows the test was accepted. The result shows hypothesis is accepted. It means display is affecting customer satisfaction base on different age or generation.

\section{Factor 6: Location \\ Sub Hypotheses 6a}

$\mathrm{Ha}$ : McDonald is located in a strategic location affect customer satisfaction in McDonald

Ho: McDonald is located in a strategic location does not affect customer satisfaction in McDonald

This table is the analysis of variance (ANOVA) test among the variable rate of purchase product at McDonald in Bandung and regarding to location base on age before making decision a purchase on a McDonald. In this test, looking up in location is the independent variable, this test looking up rate of purchase as a dependent variable. The result are being demonstrated: $p$-value $=0.834>\alpha=0.05$

From this figure, the alpha value $\alpha$ is smaller than the $p$ value. When alpha value is smaller than $p$-value, the result shows the test was rejected. The result shows hypothesis is rejected. It means loccation is affecting customer satisfaction base on different age or generation.

\section{Sub Hypotheses 6b}

$\mathrm{Hb}$ : McDonald Public transportation can easily access McDonald affect customer satisfaction in McDonald

Ho: Public transportation can easily access McDonald does not affect customer satisfaction in McDonald

This table is the analysis of variance (ANOVA) test among the variable rate of purchase product at McDonald in Bandung and regarding to location base on age before making decision a purchase on a McDonald. In this test, looking up in location is the independent variable, this test looking up rate of purchase as a dependent variable. The result are being demonstrated: $p$-value $=0.247>\alpha=0.05$

From this figure, the alpha value $\alpha$ is smaller than the $p$ value. When alpha value is smaller than $\mathrm{p}$-value, the result shows the test was rejected. The result shows hypothesis is rejected. It means location is affecting customer satisfaction base on different age or generation.

\section{Sub Hypotheses 6c}

Hc: McDonald is located in an easily accessible location affect customer satisfaction in McDonald

Ho: McDonald is located in an easily accessible location does not affect customer satisfaction in McDonald

This table is the analysis of variance (ANOVA) test among the variable rate of purchase product at McDonald in Bandung and regarding to location base on age before making decision a purchase on a McDonald. In this test, looking up in location is the independent variable, this test looking up rate of purchase as a dependent variable. The result are being demonstrated: $p$-value $=0.034<\alpha=0.05$

From this figure, the alpha value $\alpha$ is bigger than the $p$ value. When alpha value is bigger than $p$ value, the result shows the test was accepted. The result shows hypothesis is accepted. It means location is affecting customer satisfaction base on different age or generation.

\section{Sub Hypotheses 6d}

$\mathrm{Hd}$ : McDonald is located near the neighborhoods affect customer satisfaction in McDonald

Ho: McDonald is located near the neighborhoods does not affect customer satisfaction in McDonald

This table is the analysis of variance (ANOVA) test among the variable rate of purchase product at McDonald in Bandung and regarding to location base on age before making decision a purchase on a McDonald. In this test, looking up in location is the independent variable, this test looking up rate of purchase as a dependent variable. The result are being demonstrated: $p$-value $=0.031<\alpha=0.05$

From this figure, the alpha value $\alpha$ is bigger than the $p$ value. When alpha value is bigger than $p$ value, the result shows the test was accepted. The result shows hypothesis is accepted. It means location is affecting customer satisfaction base on different age or generation.

\section{Sub Hypotheses $6 e$}

He: McDonald has a clear indication of the location affect customer satisfaction in McDonald

Ho: McDonald has a clear indication of the location does not affect customer satisfaction in McDonald

This table is the analysis of variance (ANOVA) test among the variable rate of purchase product at McDonald in Bandung and regarding to location base on age before making decision a purchase on a McDonald. In this test, looking up in location is the independent variable, this test looking up rate of purchase as a dependent variable. The result are being demonstrated: $p$-value $=0.194>\alpha=0.05$ 
From this figure, the alpha value $\alpha$ is smaller than the $p$ value. When alpha value is smaller than $\mathrm{p}$-value, the result shows the test was rejected. The result shows hypothesis is rejected. It means location is affecting customer satisfaction base on different age or generation.

Summary of Hypotheses

\begin{tabular}{|l|l|}
\hline Hypotheses Path & Hypotheses Result \\
\hline H1: Price & $\begin{array}{l}\text { The Hypothesis is } \\
\text { accepted }\end{array}$ \\
\hline H2: Quality & $\begin{array}{l}\text { The Hypothesis is } \\
\text { accepted }\end{array}$ \\
\hline H3: Promotion & $\begin{array}{l}\text { The Hypothesis is } \\
\text { accepted }\end{array}$ \\
\hline H4: Staff & $\begin{array}{l}\text { The Hypothesis is } \\
\text { accepted }\end{array}$ \\
\hline H5: Display & $\begin{array}{l}\text { The Hypothesis is } \\
\text { accepted }\end{array}$ \\
\hline H6: Location & $\begin{array}{l}\text { The Hypothesis is } \\
\text { rejected }\end{array}$ \\
\hline
\end{tabular}

\section{CONCLUSION}

Price is very Affecting in Customer Satisfaction. it is because price is a crucial factor in running the business. in this research price have 6 variables. from 6 variable 2 was rejected and 4 was accepted. two variable was rejected is about the "Mcdonald display the price clearly". base on this research what Mcdonald do is not really satisfy with price in Mcdonald. the problem is Mcdonald not put the fix price of the product. Mcdonald put price without tax and service. it make customer not satisfy.

Quality and promotion in mcdonald has 5 variable questions. Base on this research all question was accepted. It means customer satisfaction with quality of mcdonald. Mcdonald can control quality and taste of they food. How make a constant taste is already apply by mcdonald. For the promotion mcdonald is doing well to make customer will to buy mcdonald. Promotion using partnership with other company like bank or other company is the best way using by mcdonald.

Staff is important element in business. Base on this research that has 6 variable questions about mcdonald staff. This research got analysis 5 variables was accepted and 1 variable was rejected. The one, which rejected is about faster response by staff in response to customer demands. Quality of sales personnel and skill they have become a problem. How they response customer request faster is still haven't done by mcdonald. This affect is customer satisfaction with mcdonald.
In display this research have 6 variables. Base on this research, 3 variables were rejected and 3 variables were accepted. 3 variable was rejected are about enough table and chair dining, cleanliness of the store, and children facilities. This 3 factor affected the customer satisfaction. Bandung habit is not like us habit or europe habit. Self-service in indonesia is not until cleaning the table. It is need a staff to clean the table after finish dining food. The slow response in staff personnel will affect display of the store. This will decrease customer satisfaction.

Location is only one factor was rejected by this research. With the advance technology now customer can get they mcdonald in anywhere. With delivery service mcdonald location is not really important element know. Know customer can booking using web site, call center, and application in they android or apple device. It more make customer satisfaction increase.

The most factor, which have biggest impact, are quality and promotion. Quality and promotion have the lower significant. All value in quality and promotion factor was accepted. It mean quality and promotion are the most influencing factors.

\section{REFERENCES}

Belch, G. \& Belch, A. (2010). Advertising and Promotion: An Integrated Marketing Communications Perspective. McGraw-Hill Education. New York.

Cooper, D. \& Schindler, P. (2013). Business Research Methods. McGraw-Hill Higher Education. New York.

Cravens, D. \& Piercy, N. (2012). Strategic Marketing. McGraw-Hill Education. New York.

Ho, R. (2014). Handbook of Univariate and Multivariate Data Analysis with IBM SPSS. CRC Press.

Kotler M (2010) Information perception: A strategic gap. Competitive Intelligence Review. 2 (2), 2-5.

Kyungok Huh (2014) Consumers' purchase behavior type, reliability and satisfaction for advertisement and personal information, and consumer purchase behavior across personality. Journal of Consumption Culture. 17 (2), 63-84.

Kweeswara, V. L. (2016) Understanding customer satisfaction and behavior strudy in Mcdonal. HELP University, Kuala Lumpur, Malaysia

at: http://www.mcdonalds.co.id (accessed 08/ 11/ 16).

McDonald (2016) [Online] Available at: http://www.mcdonalds.co.id/promo (accessed 08/10/16). 
Mulyosari (2016) Faktor yang Mempengaruhi Penentuan Lokasi Gerai Makanan Cepat Saji Studi Kasus McDonald's Mulyosari Surabaya. [Online] Available at:
https://www.scribd.com/doc/251367886/Fakto r-yang-Mempengaruhi-Penentuan-LokasiGerai-Makanan-Cepat-Saji-Studi-KasusMcDonald-s-Mulyosari-Surabaya.

\section{Copyright holder:}

Vincentius Leonardo Kweeswara, Hadi Kusumah (2020)

\section{First publication right :}

Journal of Social Science

This article is licensed under:

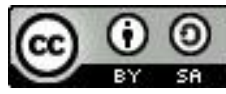

